HEATHER JOSHI, BILAL NASIM AND ALISSA GOODMAN

\title{
11. THE MEASUREMENT OF SOCIAL AND EMOTIONAL SKILLS AND THEIR ASSOCIATION WITH ACADEMIC ATTAINMENT IN BRITISH COHORT STUDIES
}

\section{INTRODUCTION}

The British Birth Cohort Studies are multi-purpose, multi-disciplinary longitudinal studies with a host of potential applications, separately or in comparison with each other and with cohort studies in other countries. This chapter illustrates how the data they collect prospectively on social and emotional skills in childhood can be linked to educational attainment at a range of stages, and how these relationships can be analysed in the context of other features of a child's family background. Before presenting our own new results on how social and emotional skills at age 10 can be traced into the academic attainments of the cohort born in Britain in 1970, we review some of the existing attempts to measure 'non-cognitive' skills and their outcomes in other literature using the national British Cohort Studies.

First a brief introduction to the four national birth cohort studies in the UK (a fifth UK national birth cohort study is in its early stages of development at the time of writing and is not included here).

The first national birth cohort study, the Medical Research Council's National Study of Health and Development (NSHD), started, in 1946, as a survey of postwar maternity services, in anticipation of the birth of the National Health Service (Wadsworth, Kuh, Richards, \& Hardy, 2006, Wadsworth, 2010). It aimed to recruit all births in a week, using health visitors to collect the data from mothers. In 1948 the study became longitudinal with the follow-up of a stratified sub-sample $(5,632)$, which was as much as resources permitted from 13,687 initial interviews. That cohort was then followed up at frequent intervals in childhood, and less frequent intervals in adulthood. The study is still ongoing with the most recent data collections at around age 63, and a new follow-up planned at age 70. Since 1961 its funding has been largely for medical enquiry. It has emphasised health information, but the life histories recorded have also had applications to social, educational and economic issues, including for example an influential contribution in its time in the debate over selective secondary education.

The second oldest national birth cohort, from 1958, was also initiated as a study of maternal and perinatal health in a cohort born in Great Britain in a week, of March 1958. In 1965 it became longitudinal, at that point to inform the Plowden 
enquiry on primary education, and became known, to this day, as the National Child Development Study (NCDS). It is now mainly supported by the ESRC and housed at the Centre for Longitudinal Studies (CLS) at the UCL Institute of Education (Power \& Elliott, 2006). The original cohort included over 17, 000 births and the follow-ups in childhood additionally recruited immigrant children within the study birth dates. Table 1 summarizes the types of data collected sweep by sweep. This shows that the fifth follow-up (NCSD5) at age 33 was particularly complex, including a supplementary survey of a sub-sample of the cohorts', children already born by 1991, but these children themselves have not (to date) been followed up. The numbers in the bottom row of Table 1 show that NCDS, like indeed most other longitudinal surveys, suffered attrition through the contacts at ages $7,11,16$; in childhood and up to 55, so far, in adulthood, with the next survey in preparation for age 60 in 2018.

The British Birth Cohort Study of 1970 (BCS70) is also now housed at CLS (Elliott \& Shepherd, 2006). It too started with all births in a week across the country, but with the intention to follow up from the outset. The longitudinal study is also based on Great Britain. The surveys at age 5 and age 10 were run from Bristol University, the one at age 16 was put in the field by an independent charity. The ESRC funded a postal survey at age 26 ensuring that the follow-up continued into adulthood, and has subsequently supported follow-up at four year intervals, age 29/30, 34, 38 (a telephone survey) and a face-to-face interview again at age 42, in 2012. A 'biosocial' follow-up (combining biomedical and social data) is planned in 2016 when cohort members are age 46.

No new national birth cohort study was initiated until the Millennium Cohort Study (MCS). The subjects of this fourth national cohort were born shortly after the turn of the millennium. At the first survey the MCS children were 9 months old, and families were then followed up when the cohort child was 3, 5, 7 and 11, in 2012 when the children were in their last year of primary school. A sixth survey is in train at age 14 in 2015, with another one planned at age 17 in 2018 . The intention is to keep following this cohort too into adulthood, but as yet the cohort has not produced evidence of the educational attainments they will carry into adult life, so they do not figure further in this chapter. See Connelly and Platt (2014) for some of the applications of the study to health matters.

Other British cohort studies outside the scope of this review include ALSPAC (Avon Longitudinal Study of Parents and Children), following children born in the Avon area around Bristol in 1991-1993, and Next Steps, formerly the Longitudinal Study of Young People in England, a cohort of English school children born in 1989-1990 which starts around age 14.

\section{INFORMATION ON NON COGNITIVE SKILLS IN BRITISH COHORT STUDIES}

The interest in non-cognitive factors in childhood as predictors and determinants of educational and other adult attainment mostly post-dated the childhoods which were 
THE MEASUREMENT OF SOCIAL AND EMOTIONAL SKILLS

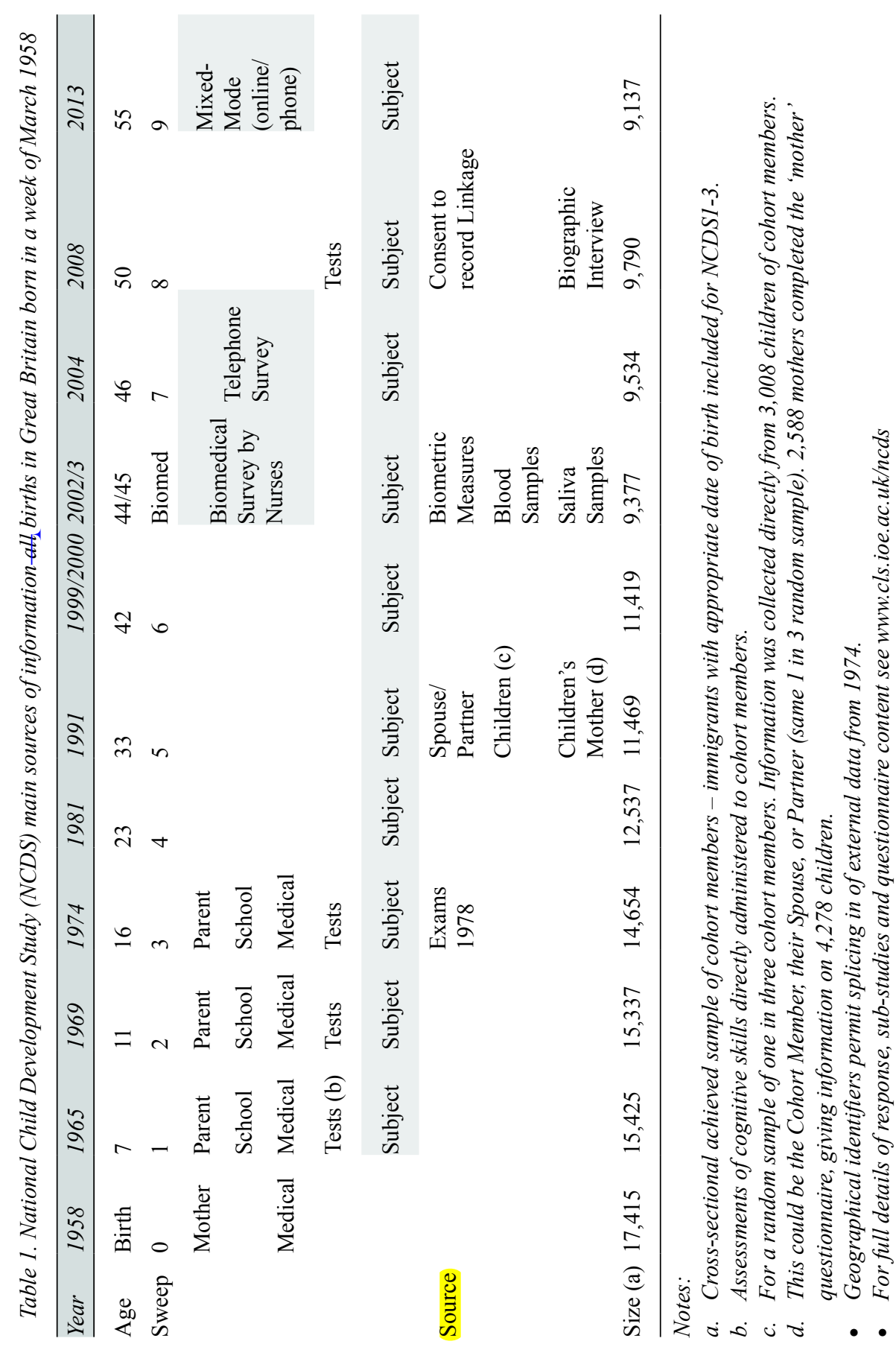


H. JOSHI ET AL.

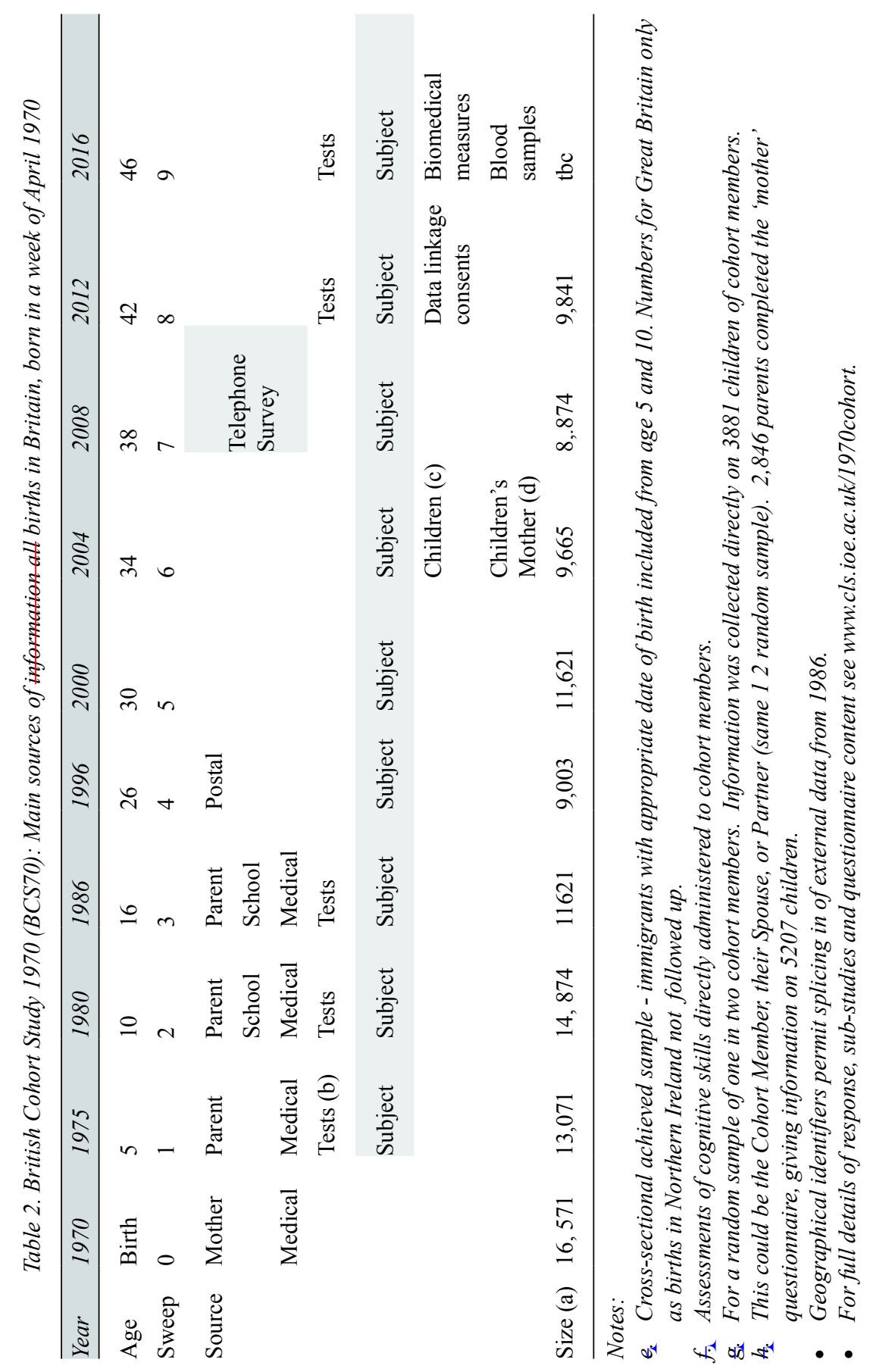


being observed in these studies. Heckman (2000) started a spate of interest, although this idea was not unprecedented; Harris (1940), and Jencks (1979) for example, had raised the question of what determines success in college and beyond. However, researchers have made use of the evidence collected at the time to approximate concepts which crystallized later.

Cohort studies not only follow individuals through time, but they reflect the times in which they are collected, and the sets of questions ('instruments') used in surveys to detect, or subsequently to proxy social and emotional skills have been changed in important ways over the years.

Especially in the case of the earliest sources, the main evidence from these studies about social and emotional skills comes from questions (to parents or teachers) about behavioural problems and difficulties from instruments such as the Rutter scales (Rutter, Tizard, \& Whitmore, 1970), while their descendants in Goodman's Strengths and Difficulties Questionnaire (SDQ, Goodman, 1997) are prominent in later studies (such as the Millennium Cohort Study). The Rutter behaviour inventories were developed in the mid-1960s for a cross-sectional study of children's health, education and behaviour in the Isle of Wight. The objective of that research was to identify and understand 'handicap', or obstacles to development, in all three domains, rather than the positive end of each spectrum. In the behavioural domain they were particularly interested in what leads to 'delinquency'. Rutter's behaviour problems questionnaire was used, as a screening device for psychiatric problems and treatment. Screening was also the prime purpose of Goodman's instrument which has replaced it in wide use. On their original purpose, these measure child mental health problems as much as, if not better than, 'skill', particularly where they focus on difficulties rather than positive strengths. The absence of the problems which they capture does not necessarily entail good socio-emotional skills, but their presence is often taken to indicate poor skills.

The language used to describe the data instruments and the concepts to which they are related have, gone in and out of fashion in different disciplines, and at different periods of time. For example the general set of attributes being referred to in this chapter have been variou. $Q$ dentified as behavioural adjustment, personality, non- cognitive skills, socio-emotional skills, and character skills, to name but a few.

\section{A LITERATURE REVIEW OF FINDINGS ON SOCIAL AND EMOTIONAL SKILLS AND THEIR LINKS TO EDUCATIONAL ATTAINMENT IN THE BRITISH BIRTH COHORT STUDIES}

\section{Cohort Study}

In the 1946 cohort surveys in the 1950s there were a few questions to the mother on child behavioural adjustment, at age 8 , in 1954, and to teachers at age 10, with items featuring aggression and nervousness, in some ways a precursor of the 
Rutter and Strengths and Difficulties instruments which were developed in the following decades, but not much use has been made of that material in the analysis of educational outcomes. There is much richer information gathered from teachers at age 13 and 15 on temperament, behaviour, attentiveness, including questions described as a close forerunner of the Rutter scale. From this material, Colman et al. (2009) derive measures of conduct and emotional problems. There were no questions aimed at identifying hyperactivity in the 1946 cohort, so the terms conduct and externalising are used interchangeably (in later data, such as SDQ, externalizing problems are the sum of hyperactivity and conduct problem subscales). Colman et al. (2009) show that severe and mild externalizing problems in childhood are related to failing to obtain any qualification, along with a range of mid-life outcomes (mental disorder, alcohol abuse, relationship difficulties, low social class, unemployment, and financial difficulties). The odds ratio they estimate for having no qualifications was 2.3 for mild conduct problems, and 4.0 for severe problems (adjusted for sex, father's social class, cognitive ability, and depression/anxiety in adolescence). In a similarly adjusted model, Richards and Abbott (2009) show that conduct problems in adolescence predict a poorer chance, for both sexes, of obtaining advanced qualifications (A level or higher) as well as a greater chance of getting no qualifications. By contrast emotional problems (in a model adjusted for class, cognition and conduct), were only significant, and to a lower extent, in raising the odds of girls getting no qualifications. Richards and Abbot (2009) report broadly similar results in a parallel analysis of the 1958 cohort (though emotional problems appeared even less of a disadvantage for educational attainment). They also show conduct problems associated, among other outcomes, with lower hourly earnings, which appears to work through education, which is not controlled in the model predicting earnings. Richards and Huppert (2012) also extracted a rating of positive attitude and social skill from the NSHD teacher material at 13 and 15 , which is rare in the literature generally emphasising behaviour problems and psychopathology. The items were: 'very popular with other children' (age 13 only); and at both 13 and 15: 'unusually happy and contented', 'makes friends extremely easily' and 'extremely energetic, never tired; with a maximum score of 7 . The rating as a 'positive child' is included as a predictor of various aspects of adult well-being, including educational attainment, alongside conduct and emotional problems, and a measure of extraversion derived from the survey members themselves when they completed a Personality Inventory at age 16. Having at least 2 out of 7 positive ratings was associated with several aspects of mid-life well-being, but not with educational attainment at A level or above, once father's class, cognition and other aspects of the child's mental health were controlled. Neither extroversion nor emotional problems were associated with 'advanced' qualifications, although the association of conduct problems with lower qualifications was also apparent here. 


\section{8 and 1970 Cohort Studies}

Despite fewer surveys in childhood, the 1958 and 1970 cohorts have more material on children's non-cognitive characteristics and much more analyses linking them to educational qualifications. The mothers were asked about behaviour problems on various versions of the Rutter behaviour problems questionnaire at 7, 11 and 16 (NCDS) and 5, 10 and 16 (BCS70). Teachers reported on a Rutter instrument at 16 in both cohorts and at age 10 and 5 in BCS70. Teachers of the 1958 cohort completed the Bristol Social Adjustment Guide (BSAG) at ages 7 and 11 (Stott, 1969). Stott shared Rutter's interest in 'Troublesome Children' (Stott, 1966). At 16 members of both cohorts provided self-assessments of their academic motivation and academic self-concept. The 1970 cohort is notable for having obtained evaluations of locus of control and self esteem from the 10 year old respondents. The former attempts to tap the extent to which the child feels events are beyond or within his/her control. It used the CARARLOC instrument developed by Gammage (1975) based on Nowicki and Strikland (1973) and derived from Rotter (1966). Self Esteem was measured on a set of questions (LAWSEQ) developed around that time by Lawrence (1981) following Rosenburg (1965). The 1970 cohort collected some detailed questions on child developmental behaviours from the teacher questionnaire, from which some researchers have inferred elements of personality and from which we draw an indicator of conscientiousness, used below but at no point in the childhood of these cohorts was the full OCEAN 'Big Five personality inventory administered (Digman, 1990). Time is always short on a multi-purpose survey instrument.

The BSAG taken at two time points in the 1958 cohort is one of the major sources of evidence on behaviour, and potentially 'non-cognitive' 'skills'. This contained 250 descriptions of behaviour put to teachers at age 7 and 11, with a form of response involving single and double underlining. So far, the results are only available in a reduction of the original items into 12 domains or syndromes, arguably idiosyncratically defined as: (1) Anxiety for acceptance by children; (2) Hostility towards children; (3) Hostility towards adults; (4) Writing off adults and standards; (5) Withdrawal; (6) Unforthcomingness; (7) Depression; (8) Anxiety for acceptance by adults; (9) Restlessness; (10) Inconsequential behaviour; (11) Miscellaneous symptoms; (12) Miscellaneous nervous symptoms. These emphasise problem behaviour, rather than the more positive responses that could be, and were, given, but which were not coded at the time. The raw BSAG data could yield more valuable information if it were more completely coded and re-grouped to reflect more current understandings of social and emotional concepts, as well as to record positive aspects of the child's behaviour as well as the problems.

Carneiro, Crawford and Goodman (2007) for example, use an overall BSAG score as a measure of 'Social skills'. Conti and Hansman (2013) look at individual domains. Ghodsian (1977) proposed a factor analysis of the 12 Domains into 
two major dimensions, internalizing and externalizing problems, notionally at least picking up the same latent characteristics as had been given the same labels (though from different questions to) in the 1946 cohort. Other authors use principal components analysis to construct their own indices of 'personality traits'. Silles (2010), for example, generated scales for aggression (partitioned into active and passive elements) and withdrawal, which were used alongside family background and cognitive score to predict earnings at 23 . She concludes that 'social maladjustment scores are strongly associated with success and failure in both education and the labour market. Daly, Delaney and Baumeister (in progress) use elements of the BSAG to capture self-discipline, or self-regulation. Papageorge et al. (2015) confirm a negative effect of externalising behaviour at 7 and 11 - derived from BSAG at 7 and 11 - on educational attainment, but suggest that there may be a positive 'return', to weekly earnings, to having been more aggressive or disruptive in class, when cognition, internalising problems and school attainment are controlled. Note that the apparent contradiction with Richards and Abbott (2009) could be due to controlling for schooling or a different measure of earnings. They draw a policy conclusion from this that measures to stamp out bad behaviour could have unintended long-term consequences which could be avoided if the policy were instead to adapt teaching style towards the more disruptive child.

Goodman, Joyce and Smith (2011) use NCDS data from birth to 50 to investigate the 'long shadow of ill-health in childhood'. They include summaries of physical and mental health problems in childhood in models of social and economic outcomes at the age of 50, finding childhood mental health to be very important for most of the outcomes they consider, including cognitive function at the age of 50 . They assess child mental health problems using reports from the school medical officer and from parents about whether the child had ever been referred to a professional for psychological or behaviour problems, rather than teacher reports from the BSAG or parent reports of behaviour problems (although they are doing so in current work). The age 50 assessment of personality is treated, not as a predictor of career success (as is questionably done by O'Connell \& Shaikh, 2011 and Furnham \& Cheng, 2013), but as one of the outcomes to be explained at the half-century mark. Three of the 'Big Five' dimensions do turn out to be significantly associated with good childhood mental health (Agreeableness, Conscientiousness and Emotional Stability), each to the tune of about 1.6 standard deviations. There was no effect on Extraversion or Intellect/Openness. While this paper does not report the effect of mental health problems in childhood on educational attainment, it does show that educational attainment in adult life does not appear to be a significant pathway through which socio-economic outcomes (such as family income at age 50) are negatively affected.

While freedom from behaviour and emotional problems may be features of non-cognitive skill, another feature commonly cited is motivation. Aspiration and expectation are less generally thought of as 'skills' though they may feed into motivation. In both NCDS and NCDS there was an attempt to assess motivation, at 
least in the classroom context, in questions directly put to sixteen year olds. Sacker and Schoon (2007) used the response on academic motivation, along with academic self-concept (how good the student thinks they are at various subjects), the cohort member's expectations and aspirations for further study, and parental interest, aspirations and expectations, to investigate who stayed on at school at 16, and who went on to gain further qualifications. In the NCDS cohort, 62 percent left school at age 16 , but some of these leavers ( $8 \%$ of the cohort) went on to return to full-time education by age 42 . Family support and personal assets were, as expected powerful predictors of staying on at school and less so eventual qualifications, given whether or not their child left. In a multivariate model, the cohort members' own expectations and aspirations at 16 were significantly associated with staying on at school, and (mostly) with eventual qualifications. Academic self-concept was not independently related to staying on at school, neither was academic motivation, for boys. It did contribute modestly to the chances of girls' staying on and to the model explaining eventual qualifications for both sexes, where there were also some significant but modest effects detected for academic self concept. Very little was significantly associated with resuming full-time education apart from academic motivation and cognitive ability. Schoon, Parsons and Sacker (2004) use similar variables from NCDS on aspirations (parent and child) and motivation to predict exam results. This paper also includes a behavioural adjustment variable based on the Rutter scale. Both motivation and good behaviour are better at predicting exam results among the relatively advantaged sub-sample than among their disadvantaged counterparts. Among other research making use of this information is Schoon's (2008) comparison of the pathway from childhood to adult social status, via educational attainment with direct and indirect influences of cognitive ability and motivation. Educational attainment was measured as the highest level attained on leaving full-time education, and adult social status was a combination of the social class of occupation at age 33/30 and highest qualification attained by that date. She shows that the major determinant of adult status is educational attainment, particularly for the 1970 cohort, but that both cognitive ability and motivation both feed into educational attainment and have an independent effect on adult social status beyond that. The effect of motivation on educational attainment is slightly stronger for females than males, while the reverse is true for the direct effect of 16 year old motivation on status in at 33/30. Further research using motivation variables is reviewed by Goodman, Joshi, Nasim and Tyler (2015).

While resilience - the ability to withstand an adversity or shock or recover from one - is often listed as a trait which helps people survive and 'beat the odds', it is not something that surveys can measure directly in people, in particular in those who might be exposed to a shock but have not experienced it. Resilience has been inferred in analyses of the British birth cohort studies by, for example, Schoon (2006). Children from disadvantaged backgrounds who emerge from school in the top half of the educational attainment distribution are said to be 'resilient'. Children from disadvantaged backgrounds with lower educational attainments are classified 
as 'vulnerable'. The 'resilient' individuals also do 'better than expected' in a number of adult outcomes on the labour market and psychological domains, in various ways, sometimes differing for men and women. Among factors with some relationship to explaining who beat the odds were own and parental aspirations and expectations, and parental support (see also Sacker \& Schoon, 2007).

The mother's questionnaire about child behaviour at age 10 in the 1970 cohort (Rutter) has been used to yield 3 components, hyperactivity, conduct and emotional problems, the first two often being combined as externalising problems (Maughan, Taylor, Taylor, Butler, \& Bynner, 2001). Hyperactivity (loading on restlessness, fidgetiness, and lack of concentration at age 5) was one of the terms included in Flouri's model of educational attainment at 26 (Flouri, 2007). Along with authoritarian parenting it was one of two risk factors associated with low attainment at 26 , however hyperactivity made less difference if the child was living in a 'lowstimulation environment' (maternal depression and low maternal educational attainment), just as authoritarian parenting was not related to educational attainment within the lower social class families.

At age 10 the children's responses on their locus of control has been related to educational outcomes by a number of authors: Feinstein (2000), Flouri (2006), Murasko (2007), Conti, Heckman and Urzua (2011). After controlling for parental background and other socio-emotional characteristics at 10, Feinstein found a significant boost to qualifications by 26 from an internal locus of control (belief in own agency) along with teacher-rated 'Attentiveness' at 10. Murasko looked at both the CARALOC locus of control inventory and the LAWESEC inventory on self-esteem. In a model which controlled also for cognitive ability, health, social background, he found that only an internal locus of control, and not self-esteem was significantly related to continuing training beyond the compulsory school age of 16 .

The mother's Rutter questionnaire at age 10 in the 1970 cohort has also been used to capture the concept of self-regulation. For example, O'Reilly, Daly and Delaney (in progress) show that self-regulation is positively associated with a number of measures of educational attainment.

In a recent review of social and emotional skills commissioned by the Early Intervention Foundation, Goodman et al. (2015) use evidence derived from a number of child and teacher items at age 10 in the 1970 cohort to show that internal locus of control, positive academic self-concept, good conduct and conscientiousness (together taken to reflect self-regulation) are all positively associated with the chances of obtaining a degree. The strongest single predictor of educational attainment, however, is cognitive ability. Interestingly, social skills are negatively associated with obtaining a degree, although this is observed only for boys. This report also looked at 19 other adult outcomes in various economic, social and health domains. Estimates were made of how many of the links between childhood skills and adult outcomes worked through effects on education. This was particularly frequent in the case for cognitive ability: in total 11 out of 19 outcomes were partially or totally mediated by education, particularly for economic outcomes like 
wages and net wealth. This also applied to locus of control and conscientiousness in 7 and 5 outcomes, respectively, mostly on the labour market. The association of good conduct, (or the absence of externalising problems), with occupational status was partly accounted for by education; its link to life satisfaction, adult heath, and family income in adulthood appeared to work entirely via education. They note that there was not sufficient evidence of motivation or 'resilience' at age 10 to include it the analysis of BCS70, nor for the same reason does it, or the present study, attempt to assess the notion of 'grit', reflecting passion and perseverance, which has been linked to resilience, as there have only recently been attempts to measure it (Duckworth, Peterson, Matthews, \& Kelly, 2007).

\section{ANALYSIS OF THE 1970 COHORT STUDY}

In the remainder of this chapter we set out some new empirical analysis of the British 1970 birth cohort showing the association between cognitive, social and emotional skills in mid-childhood and educational attainment by age 30 .

\section{Measuring Non-Cognitive Skills and Family Background}

Non-cognitive skills. We use the following conceptualisation of four dimensions of social and emotional skills measured at age 10, described more fully in Goodman et al. (2015), which in turn builds heavily on Gutman and Schoon, (2013).

1. Self-perception and self-awareness, which relate to a child's knowledge and perception of themselves and their value, and their confidence in their current abilities and a belief in their efficacy in future tasks, are captured by the following variables.

a. Locus of Control - The child's perception of how far things are under his/her own control (internal locus) rather than the result of external forces (external locus), based on the child's response to the CARALOC inventory.

b. Self-esteem - Based on the child's response to the LAWSEQ inventory.

c. Academic Self-concept - Child's own rating of how good s/he is at maths, reading, spelling, creative writing, arts/crafts and other topics/projects.

2. Self-control and self-regulation refer to how children manage and express emotions, and the extent to which they overcome short-term impulsivity in order to prioritise higher pursuits. Lack of self-control is comprised of six interrelated characteristics namely: (1) impulsivity and inability to delay gratification, (2) lack of persistence, tenacity, or diligence, (3) partaking in novelty or riskseeking activities, (4) little value of intellectual ability, (5) self-centeredness, and (6) volatile temper. It has elements in common with behavioural difficulties, particularly those grouped as 'externalizing'. High self-control is associated with 'conscientiousness', one of the Big Five dimensions of personality. 
H. JOSHI ET AL.

a. Good Conduct (reverse of externalizing scale) based on mother report on the Rutter inventory

b. Conscientiousness - We use selected variables from the teacher-reported Child Development Behaviour Questionnaire to form a measure which we term 'Conscientiousness'. We aggregate over 9 items relating to whether the child daydreams, becomes bored in class, shows perseverance, becomes confused, is forgetful, shows lethargic behaviour, works independently and accepts the goals of the curriculum, before standardising. Each item is on a scale of 1 to 47 , and reverse coded where appropriate such that a higher score represents greater conscientiousness.

3. Emotional Health (reverse of internalising scale) The child's emotional health is measured using the emotion subscale of the mother-reported Rutter Behaviour Questionnaire, which contains 5 items relating to what extent the child is often worried, miserable, fearful, fussy, sullen or tearful and is a measure of whe of negative feelings, otherwise known as 'emotional problems'. Each item is on a scale of 0 to 100 and the 6 items are aggregated, before standardising.

4. Social Skills (peer relationships) generally describe a child's ability and tendency to interact with others, forge and maintain relationships, and avoid socially unacceptable responses. They cover communication, empathy, kindness, sharing and cooperativeness. They are absent when a child is solitary, shy or withdrawn. Social skills are captured in our analysis by teacher-reported peer-relationship questions relating to the child. The teacher is asked to what extent the child is popular with peers, has many friends, shows bold rather than shy behaviour and is cooperative with peers. We aggregate over these four items, which are each on a 1 to 47 scale before standardising.

\section{Cognitive Skills}

We examine three domains of cognitive skill also measured at age 10 in the 1970 cohort study (see Parsons, 2014).

a. The Edinburgh Reading Test requires children to complete a variety of tasks including matching words to pictures, selecting the incorrect word in a sentence, matching answers to questions, extracting information from a picture, answering questions after reading some text, understanding the meaning of words and putting sentences in the correct order.

b. The Friendly Maths Test is a multiple choice test which includes questions on arithmetic, number skills, fractions, algebra, geometry and statistics

c. The British Ability Scale is selection from a wider suite of tests of cognitive abilities measuring something akin to IQ. It includes two verbal subscales (word definitions and word similarities) and two non-verbal subscales (digit recall and matrices). 
We utilise 7 measures of social and emotional skills, and 3 measures of cognitive skills, providing 10 distinct dimensions of childhood non-cognitive and cognitive development at age 10 . All ten measures are coded such that a higher score represents a higher level of that skill. For the analysis we convert each of the 10 measures into their respective quintiles, where the first quintile represents the bottom $20 \%$ of the distribution and the fifth quintile the top $20 \%$ of the distribution.

We estimate the effects of each of these cognitive, and social and emotional skills jointly, on the highest level of formal educational attainment by age 30, also conditioning on a wide range of other child, parent and family characteristics, and measured at various ages of the child(as indicated): child's birth weight, gender (birth), ethnicity (age 10), whether the child has older siblings (age 5), education level of parents (birth), their employment status (age 10), maternal mental health (age 5), mother's age at birth of the cohort member, family income (age 10) and social housing tenure (age 10).

Before going on to describe the educational measure in more detail we first show some descriptive statistics relating to how children's social and emotional, and cognitive skills at age 10 interrelated, and how do they differ across children and their families.

How Are Children's Social and Emotional, and Cognitive Skills at Age 10 Interrelated, and How Do They Differ across Children and Their Families?

We first show how the different social and emotional, and cognitive skills at age 10 are correlated (Table 3 ). This table shows that there are positive correlations between different skills, meaning that a child with higher skills in one dimension is likely to have higher skills in the other dimensions, too. The correlations range from the relatively low association of 0.06 (e.g. between academic self-concept and emotional health), to a high 0.74 (e.g. between maths and BAS). As a rough guide, a correlation above 0.3 is considered strong.

Within the social and emotional skills, notable are the strong correlation between locus of control and self-esteem (0.42), good conduct and emotional health (0.42) and conscientiousness and both locus of control (0.39) and sociability (0.44).

Correlations with academic self-concept are modest, it being the only skill not correlated with any other skill by more than 0.3 . Good conduct is poorly correlated with self-perception/self-awareness measures, and interestingly, with the other skill measure pertaining to self-control/self-regulation, conscientiousness. Other than conscientiousness, sociability appears only modestly associated with the other social and emotional skills.

There are stronger associations within the cognitive skills group, with reading, maths and BAS exhibiting correlations with each other above 0.7. With respect to associations between social and emotional skills and cognitive skills, it can be seen that the strongest correlations are, by some way, between locus of control 
H. JOSHI ET AL.

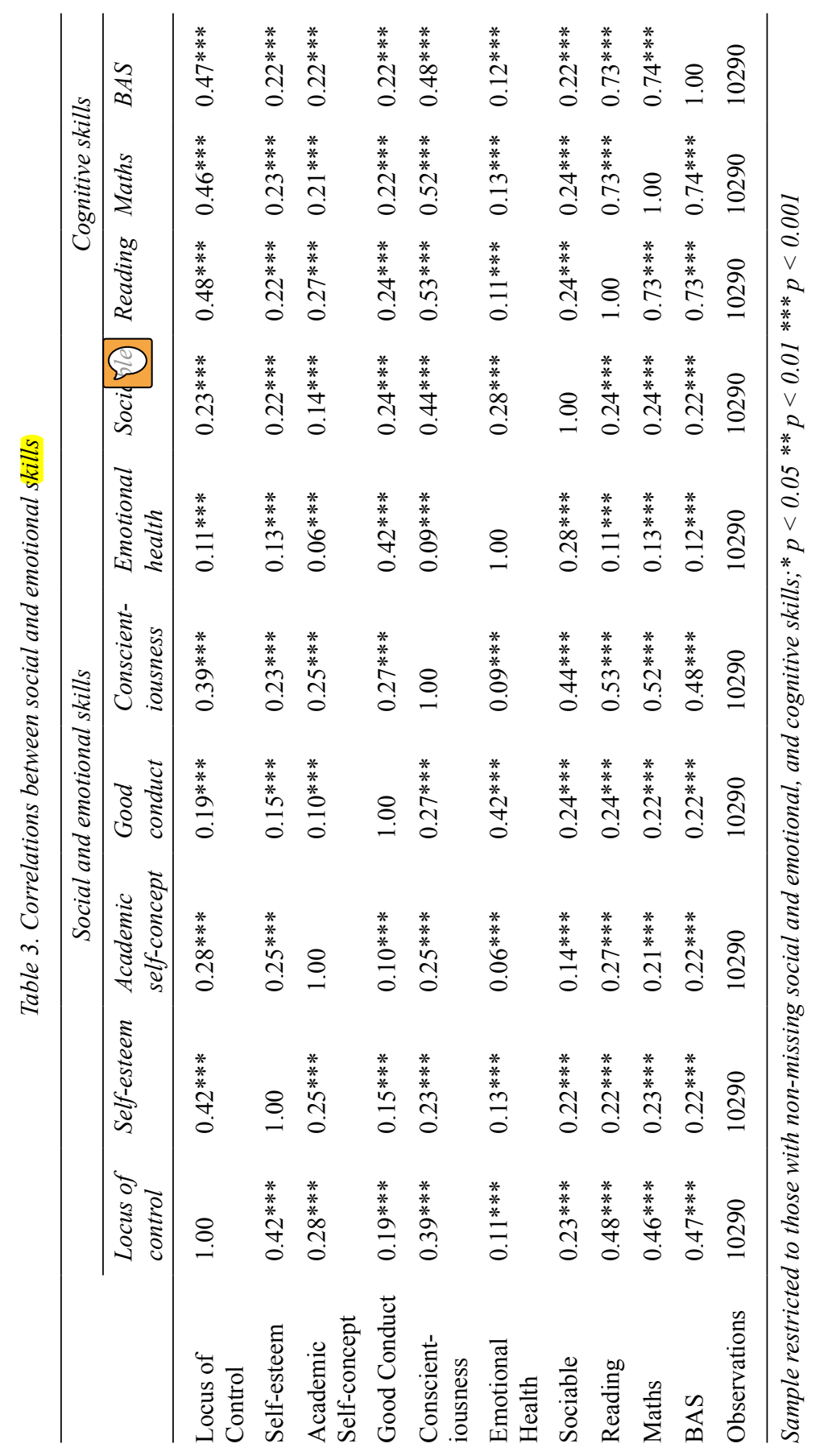


THE MEASUREMENT OF SOCIAL AND EMOTIONAL SKILLS

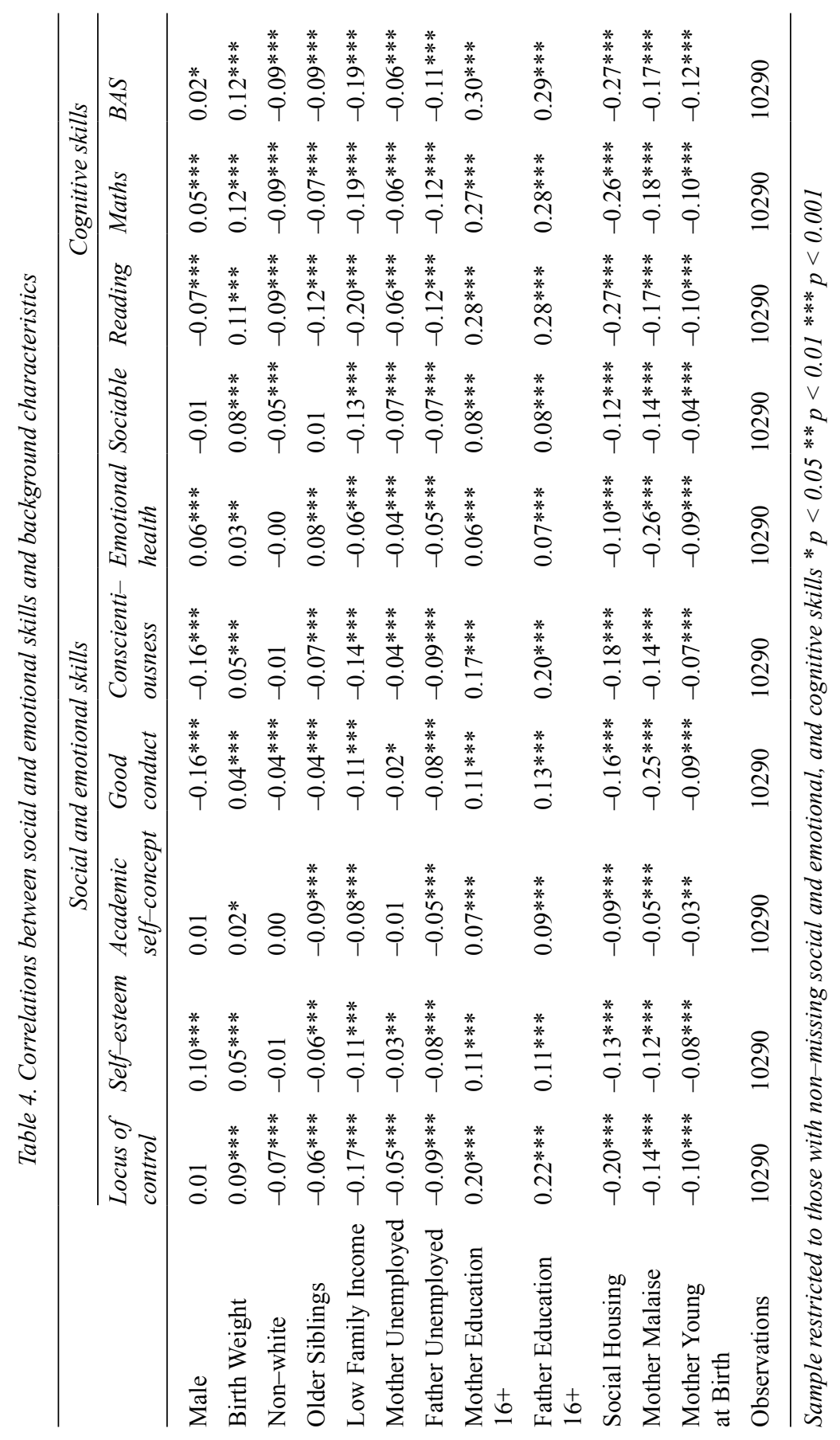


H. JOSHI ET AL.

and conscientiousness, and the three measures of cognitive skill, with correlations around 0.5 .

Table 4 shows the correlations between the social and emotional, and cognitive skills and other background characteristics of the child. It can be seen that the cognitive skills are more strongly associated with almost all of the child, parent and family characteristics, with the notable exceptions of gender and mother's malaise score (mental distress). It should be noted however, that the social and emotional skills most strongly associated with mother's mental distress are good conduct (0.25) and emotional health (0.26), which are the only two skills of the child which are mother-reported. Part of the relatively strong correlation, therefore, may be due to mother's with poorer mental health tending to report greater emotional and behavioural problems in their children than might a less depressed informant.

The three cognitive skills are most strongly associated with parental education and housing tenure, with correlations ranging from 0.26 to 0.30 . More generally, the cognitive skills are particularly strongly associated with measures of parental socioeconomic status (parental income, unemployment, education and social housing). This is also true for locus of control and conscientiousness, which were also the two social and emotional skills exhibiting the strongest associations with the cognitive measures.

\section{Measuring Highest Educational Attainment}

Our ordinal indicator of educational attainment is based on academic qualifications, namely those usually obtained in school or college, and is categorised by the highest level reached in six stages (Table 5). The sample of 7,495 represents the sample used in the analysis, and is defined by those individuals for whom we have available information on highest educational attainment and all 10 of the social and emotional, and cognitive skills.

The 1970 cohort faced a minimum school leaving age of 16 . Around that time they could sit a public examination, which took several forms. In England and Wales, there was a two tier system of CSEs (Certificate or Secondary Education, aimed at the less able) and O-levels (Ordinary level of the General Certificate of Education), which was then replaced by GCSEs (General Certificate of Secondary Education) in 1988. Cohort members therefore largely gained their exams under the two tier system, but may also have subsequently gained GCSEs from the age of 18 onwards. Students normally sat exams in 5-10 subjects, which did not all have to be done at the same time, and might be repeated to redress a failure or improve grades. There were Advanced levels of GCEs (A-levels) taken generally two years later, at the end of secondary schooling, in a smaller number of subjects (around 3). There were different but equivalent exams in Scotland. In terms of the age at which it is taken, A-levels resemble qualifications like the baccalaureate or US High School graduation, although the content of what is examined, and the standards attained are not exactly comparable. We use information on two levels of tertiary education 
THE MEASUREMENT OF SOCIAL AND EMOTIONAL SKILLS

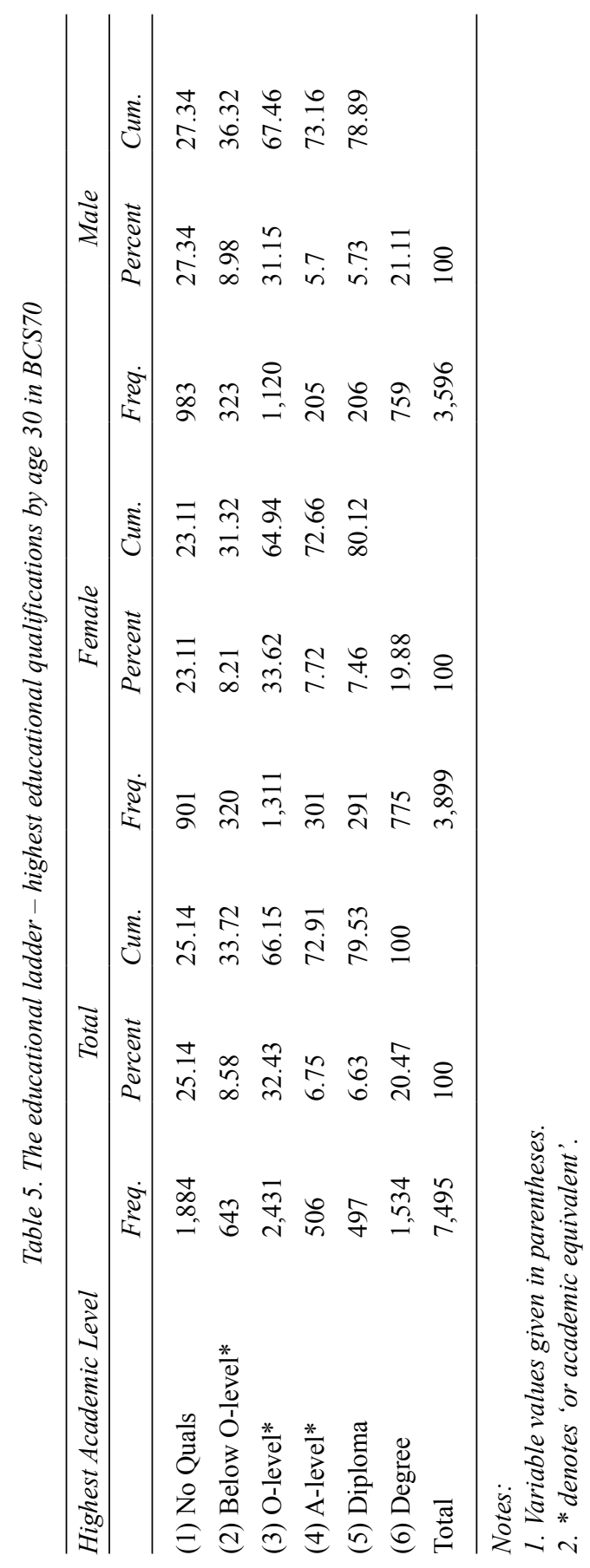


in universities and other higher education institutions; the lower level of tertiary education include qualifications such as diplomas (which may not require more than two year's study, often those days teaching diplomas) and university degrees at bachelor's and postgraduate level (both master's and doctoral). There were too few cases of postgraduate degrees to treat them separately in our analysis. Our scheme does not include vocational qualifications such as apprenticeships, which tend to be obtained once employed (and may be less strongly associated with early life antecedents or subsequent outcomes).

The lowest level, no academic qualifications, accounts for 25 percent of our total sample. These people would mostly have left school at 16, in the summer of 1976, although some would have stayed on without sitting or without obtaining passes in any public exams. Some early leavers acquired qualifications later, but these are more likely to have been vocational rather than academic.

The second level have obtained at least some passes in public exams but below the level treated as adequate for academic progression. Many of them would not have stayed on at school beyond 16. Nine per cent fall into this group.

The third threshold was passed by two thirds of the cohort. It marks the group who 'did well' in O-level/GCSE (5 passed at grades A*-C or CSE grade 1) but went no further, representing 32 per cent of our sample, the largest of the categories. Many of them, particularly girls, left school between 16 and 17, albeit with respectable qualifications.

To enter higher education it is generally required to move beyond O-levels/ GCSEs, as did about one third of our sample. 7 per cent obtained A-levels but did not progress any further, and this represents the fourth educational level in our analysis. A similar percentage, 7 per cent reached the level of a higher education diploma and no further, representing the fifth level. And finally, approximately 20 per cent of the sample obtained degrees (including 3 per cent with post-graduate qualifications).

There are slight differences between females and males in our sample, with males being more likely to obtain no qualifications, and a degree, but less likely to have intermediate outcomes as the highest level achieved.

\section{Method for Estimating the Relationship between Childhood Skills and Educational Attainment}

We estimate an ordered logit model for the ordinal dependent variable, $Y$, describing the highest level of educational attainment, where larger values (categories) correspond to "higher" rungs of the educational ladder. The ordered logit model can be written as;

$$
P\left(Y_{i}>j\right)=g\left(\beta^{S} \boldsymbol{S}+\lambda^{X} \boldsymbol{X}\right)=\frac{\exp \left(\alpha_{j}+\beta^{S} \boldsymbol{S}_{\boldsymbol{i}}+\lambda^{X} \boldsymbol{X}_{\boldsymbol{i}}\right)}{1+\exp \left(\alpha_{j}+\beta^{S} \boldsymbol{S}_{\boldsymbol{i}}+\lambda^{X} \boldsymbol{X}_{\boldsymbol{i}}\right)}, j=1,2 \ldots, M-1
$$


where $j$ is an index of the ordinal education variable, $Y, M$ is the total number of categories of (6), and the vector, $S$, represents the 10 skills, cognitive and noncognitive. The vector, $X$, denotes the array of child, parent and family characteristics included as controls.

The ordered logit model described by equation (1) is an example of a proportional odds model which assumes that the $\beta$ 's for each skill (and the $\lambda$ 's for each control) are the same for each value of $j$. In other words, the effect of a skill is the same across different pairs of educational outcome groups, giving rise to only one set of parameters. For example, this assumption would imply that the effect of a skill on the probability of not being in the bottom education category is the same as its effect on the probability of not being in the bottom two categories, and of not being in the bottom three categories, and so on. We first present these proportional odds estimates for each skill, conditional on all of the other variables in the model being held constant.

Results from the Brant test suggest, however, that the proportional odds assumption is violated for at least one, but not all, of the skills we consider; i.e. some of the $\beta$ 's differ across values of $j$. This implies that the proportional odds model estimated via the ordered logit is overly restrictive. The generalised ordered logit model can be used to address violations of the proportional odds assumption, and can be written as;

$$
P\left(Y_{i}>j\right)=g\left(\beta_{j}^{S} \boldsymbol{S}+\lambda_{j}^{X} \boldsymbol{X}\right)=\frac{\exp \left(\alpha_{j}+\beta_{j}^{S t} \boldsymbol{S}_{i}+\lambda_{j}^{X} \boldsymbol{X}_{\boldsymbol{i}}\right)}{1+\exp \left(\alpha_{j}+\beta_{j}^{S} \boldsymbol{S}_{i}+\lambda_{j}^{X} \boldsymbol{X}_{\boldsymbol{i}}\right)}, j=1,2 \ldots, M-1
$$

where the parameters $\beta^{\mathrm{s}}$ and $\lambda^{\mathrm{x}}$ are allowed to vary across values of $j$. However, the results of the Brant test also imply that the generalised ordered logit, which for each skill estimates a unique $\beta$ for each $j$, would be estimating more parameters than is necessary, as for some of the skills, the proportional odds assumption holds. We therefore estimate a special case, the partial proportional odds model, which allows the $\beta$ coefficients for some of the skills to be the same for all steps up the educational ladder (values of $j$ ) while others are free to differ, depending on whether the proportional odds assumption holds. We present estimates of $\beta$ for each of the 10 skills, from both the ordered logit (proportional odds model), and the generalised ordered logit (partial proportional odds model) for different values of $j$. The estimated coefficients presented are as percentages, conditional on the full set of controls.

Results: How Important are Social and Emotional Skills at Age for Educational Attainment by Age 30?

Table 6, below, presents our main findings, corresponding to estimates based on equations (1) and (2). It shows the effect in per cent of moving up a quintile in each social and emotional skill, and for comparison, each cognitive skill, on the 
likelihood of attaining a particular stage of education, conditional on the child, parent and family characteristics outlined above (Section 4.1). The first column displays the results from the ordered logit regression. It can be seen that of the social and emotional skills, a one quintile increase is positively associated with the likelihood of being one rung further up the educational ladder for academic selfconcept (5.4\%), locus of control (10.1\%), good conduct (10\%) and conscientiousness $(14.2 \%)$. The proportional odds assumption implies that this effect is the same irrespective of how the 'higher' and 'lower' education groups are defined (i.e. the value of $j$ in equation (1)).

As we also found in our earlier report (Goodman et al., 2015), sociability is negatively associated, albeit modestly, with the likelihood of higher levels of educational attainment. This finding has several possible interpretations: sociability may be associated with behaviours and levels of academic effort which inhibit the ability of an individual to proceed to the higher levels of attainment. However, sociable individuals may instead (or in addition) have different preferences and attitudes toward education, and the lower likelihood of attaining higher levels of education may in fact reflect the choices of those individuals. The analysis here cannot establish the mechanisms underlying this observed negative 'impact' of sociability on educational attainment.

Emotional health is also found to be negatively associated with the likelihood of higher educational attainment. In our previous work, with a slightly different sample, we also observed a negative, but insignificant estimate. Plausible interpretations for this negative association are also elusive. A sensitivity analysis of this finding suggests that the inclusion of good conduct in particular is the key skill which determines the nature of the association between emotional health and educational attainment. When good conduct is excluded, emotional health is not negatively associated with educational attainment. This suggests that the relatively high correlation between emotional health and good conduct may be driving the peculiar findings for emotional health. Self-esteem is the only skill included in our model which is not associated with the likelihood of higher levels of educational attainment.

The proportional odds model in column one also suggests that the three cognitive skills predict stronger likelihood of rising up the educational ladder than do social and emotional skills. Note in particular the estimates for maths (22.3\%) and reading $(18.9 \%)$.

Column 2 presents the p-values from the skill-specific Brant test of the proportional odds assumption. If the p-value is smaller than 0.01 , the proportional odds assumption is rejected, i.e. the effect of the skill is not the same across different pairs of outcome groups defining higher and lower rungs of the educational ladder. The Brant test does not reject the proportional odds assumption for self-esteem, academic self-concept, emotional health and the 'IQ' measure, BAS. This implies that the estimated effects of these skills do not significantly vary across different pairs of outcome groups along the educational highway. In contrast, the p-values of 
THE MEASUREMENT OF SOCIAL AND EMOTIONAL SKILLS

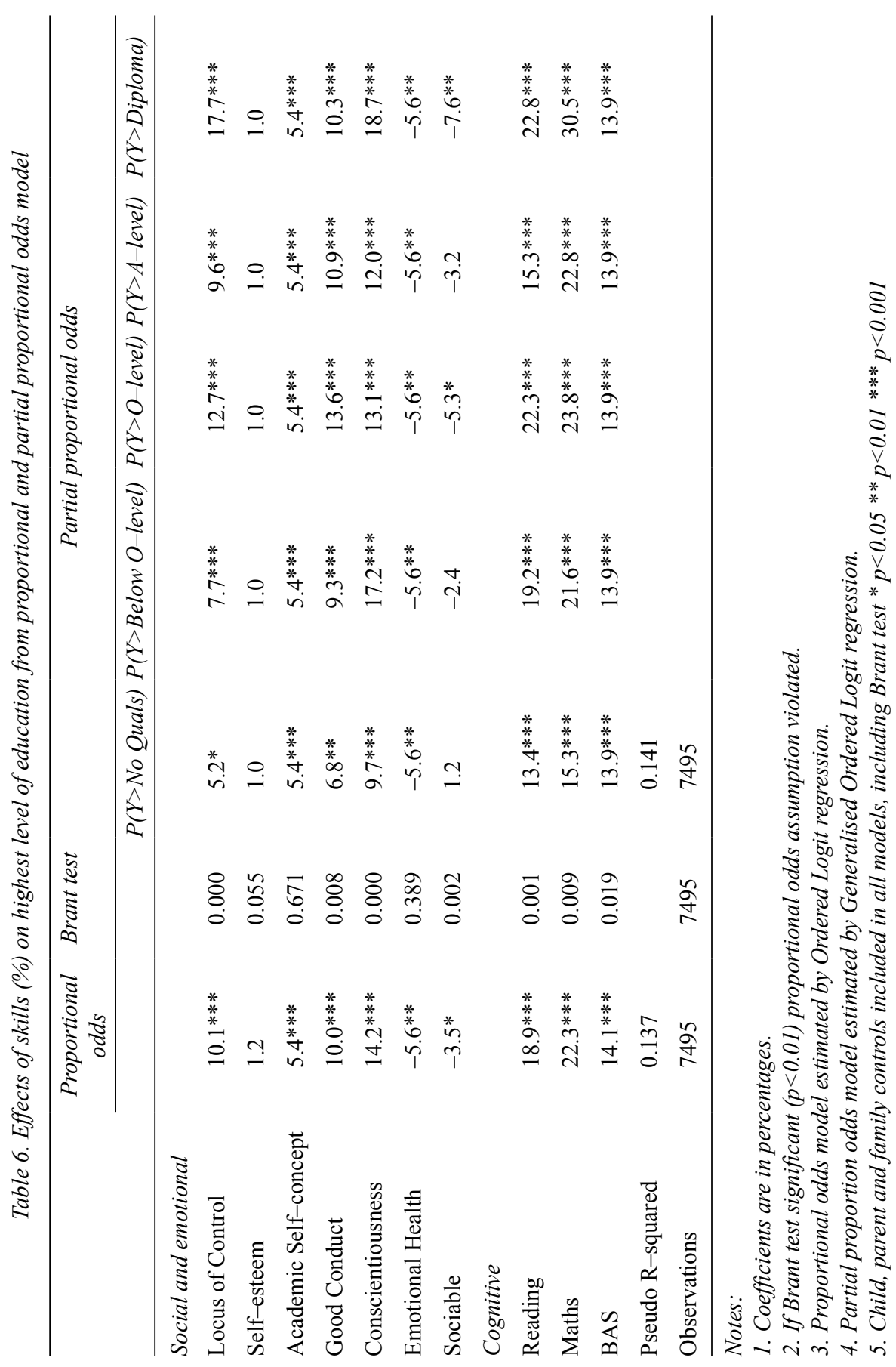


the Brant test for the remaining skills all suggest that the assumption of proportional odds is inappropriate, and that the effects of these skills vary by educational stage (across values of $j$, from equation (1)).

Columns 3 through 7 thus present the results from a generalised ordered logit, estimating a partial proportion odds model. Here, the proportional odds assumption is relaxed for those skills for which the assumption is violated, based on the Brant test. The effects of these skills are allowed to vary at each rung between educational levels. Columns $3(\mathrm{P}(\mathrm{Y}>$ No Quals $))$ through $7(\mathrm{P}(\mathrm{Y}>$ Diploma $))$ correspond to estimates based on equation (2), for values of $j$ equal to 1 through 5 , respectively.

For the skills for which the proportional odds assumption holds (self-esteem, emotional health, sociability and BAS), the estimated effect is constrained to be the same over values of $j$. Note that these estimates may not be exactly the same as those from the proportional odds model (column 1), as they are estimated from a partial proportional odds model in which other skills are not constrained. For example, selfesteem has an effect of $1.2 \%$ from the proportional odds model, and $1 \%$ from the partial proportional odds model, both not significant.

Those skills for which the proportional odds assumption does not hold, show differential effects depending on values of $j$, the level of educational attainment. Locus of control, conscientiousness, reading and maths all exhibit stronger impacts when considering the likelihood of obtaining a degree versus all lower education categories $(\mathrm{P}(\mathrm{Y}>$ Diploma $), j=5)$ than lower values of $j$. This suggests that the educational return to these skills is strongest at the transition into the highest levels of educational attainment. Maths skills also exhibit the strongest effect at this point, with a one quintile improvement associated with a $30.5 \%$ higher likelihood of obtaining a degree. The negative impact of sociability also manifests most strongly at the transitions to degree, where a one quintile increase is associated with a $7.6 \%$ reduction in the likelihood of obtaining a degree, with a smaller effect on the likelihood of progressing beyond $\mathrm{O}$ level.

Where the proportional odds assumption does not hold, estimates do not vary in any orderly sequence. The returns to many skills are relatively strong in transitioning beyond O-levels $(\mathrm{P}(\mathrm{Y}>\mathrm{O}-\mathrm{level}))$. For good conduct, this is in fact the strongest effect across values of $j$. For locus of control, reading and maths, the effect size is second only to the effect associated with the likelihood of obtaining a degree, the final column. This suggests that moving beyond O-levels is particularly sensitive to a number of the social and emotional, and cognitive skills. Conscientiousness seems particularly strongly associated with getting a foothold at $\mathrm{O}$ levels (as well as a degree). The dominance of the cognitive over social and emotional skills in predicting academic attainment applies all the stages of the educational pathway.

\section{CONCLUSION}

Our findings here confirm and extend the earlier literature using the British cohort studies that educational attainment does not depend on cognitive skill alone. 
Cognitive skills raise educational attainment particularly in getting over the hurdle to a university degree. There are also some non-cognitive skills that contribute strongly. In particular, conscientiousness and internal locus of control have a substantial association with obtaining a university education, as well as intermediate qualifications. Good conduct also appears to be particularly helpful in the middle of the range. Academic self-concept appears to give a constant proportional boost to moving up the educational ladder at all stages. Self-esteem, by contrast, does not appear to enhance the chance of academic success, although we have found elsewhere that people with higher self-esteem at $10 \mathrm{had}$, on some indicators, better mental health as adults.

Curiously, perhaps, emotionally healthy children have lower chances of academic success, all else equal, although in other work we show positive emotional health is associated with better adult outcomes in other domains. We find, here and in our previous work, a similar deficit in educational attainment for those who display social skills at age 10 . When we examine differences by gender, we find that the negative association between sociability and educational attainment is confined to males, and is not observed for females. Further, the positive educational returns to both measures of self-regulation, good conduct and conscientiousness, are found to be stronger for boys. As we saw in Table 3 boys exhibit poorer conduct and conscientiousness than girls, suggesting the higher returns to both skills may be related to the lower initial levels. Exploring the differences in the returns to the skills across other dimensions in addition to gender, such as ethnicity and levels of disadvantage, is a direction for future work.

For the educational outcome examined here, there is thus evidence of social and emotional characteristics as educationally productive skills: particularly, internal locus of control, conscientiousness and good conduct. The strength of our work lies in the quality and range of cognitive and non-cognitive skills that were captured among study members in their childhood, alongside their educational attainment up to two decades later. One limitation is that by confining attention to skills measured at age 10, we have not included measures of motivation and ambition that were actually measured later in the cohorts' adolescence. Other authors have shown that this would add to the evidence of positive skills alongside the absence of psychological pathology.

\section{ACKNOWLEGEMENTS}

We would like to thank ESRC (and all previous funders) for their generous support of the British Cohort Study (1970) and all study participants, without whom this work would not have been possible. The British Cohort Study is currently supported through the Centre for Longitudinal Studies (CLS), Resource Centre from 20152020, ESRC grant reference number: ES/M001660/1. Heather Joshi acknowledges ESRC funding under grant ES/I038187/1, 'The Role of Education in Intergenerational Social Mobility'. 
H. JOSHI ET AL.

\section{REFERENCES}

Achenbach, T. (1991). Manual for the child behavior Checklist/4 - 18 and 1991 Profile. Burlington, VT: University of Vermont Department of Psychiatry.

Ashby, J. S., \& Schoon, I. (2011). Career success: The role of teenage career aspirations, ambition value and gender in predicting adult social status and earnings. Journal of Vocational Behavior, 77(2010), $350-360$.

Carneiro, P., Crawford, C., \& Goodman, A. (2007). The impact of early cognitive and non-cognitive skills on later outcomes (CEE Discussion Paper No. 92). Retrieved from http://cee.lse.ac.uk/cee\%20dps/ ceedp92.pdf

Colman, I., Murray, J., Abbott, R. A., Maughan, B., Kuh, D., Croudace, T. J., \& Jones, P. B. (2009). Outcomes of conduct problems in adolescence: Forty-year follow-up of a national cohort. British Medical Journal, 338, a2981

Connelly, R., \& Platt, L. (2014). Cohort profile: UK Millennium Cohort Study (MCS). International Journal of Epidemiology, 43(6), 1719-1725.

Conti, G., \& Hansman, C. (2013). Personality and the education-health gradient: A note on "Understanding differences in health behaviors by education". Journal of Health Economics, 32(2), 480-485.

Conti, G., Heckman, J., \& Urzua, S. (2011). Early endowments, education and health. Human capital and economic opportunity (Working Paper 2011-001). Chicago, IL: University of Chicago.

Daly, D., \& Baumeister. (in progress). Poor childhood self-control predicts physiological dysregulation in midlife. Retrieved from http://www.cls.ioe.ac.uk/library-media $\% 5$ Cdocuments $\% 5$ CLethaby $\% 20$ Room\%20day\%201.pdf

Digman, J. M. (1990). Personality structure: Emergence of the 5-Factor Model. Annual Review of Psychology, 41, 417-440.

Duckworth, A. L., Peterson, C., Matthews, M. D., \& Kelly, D. R. (2007). Grit: Perseverance and passion for long-term goals. Journal of Personality and Social Psychology, 92(6), 1087-1101.

Elliott, J., \& Shepherd, P. (2006). Cohort profile: 1970 British Birth Cohort (BCS70). International Journal of Epidemiology, 35(4), 836-843.

Feinstein, L. (2000). The relative economic importance of academic, psychological and behavioural attributes developed in childhood. Centre for Economic Performance (Discussion Paper 443).

Flouri, E. (2006). Parental interest in children's education, children's self-esteem and locus of control, and later educational attainment: Twenty-six year follow-up of the 1970 British birth cohort. British Journal of Educational Psychology, 76(1), 41-55.

Flouri, E. (2007). Early family environments may moderate prediction of low educational attainment in adulthood: The cases of childhood hyperactivity and authoritarian parenting. Educational Psychology, 27(6), 737-751.

Furnham, A., \& Cheng, H. (2013). Factors influencing adult earnings: Findings from a nationally representative sample. The Journal of Socio-Economics, 44, 120-125.

Gammage, P. (1975). Socialisation, schooling and locus of control (PhD Thesis). Bristol University, Bristol, England. Retrieved http://www.eric.ed.gov/ERICDocs/data/ericdocs2sql/content_storage 01/ 0000019b/80/30/1a/13.pdf

Ghodsian, M. (1977). Children's behaviour and the BSAG: Some theoretical and statistical considerations. British Journal of Social and Clinical Psychology, 16(1), 23-28.

Goodman, A., Joyce, R., \& Smith, J. P. (2011, April). The long shadow cast by childhood physical and mental problems on adult life. Proceedings of the National Academy of Sciences, 108(15), 6032-6037. doi:10.1073/pnas.1016970108

Goodman, A., Nasim, B., Joshi, H., \& Tyler, C. (2015). Socio-emotional skills in childhood and their long-term effects on adult life. A review for the Early Intervention Foundation. Retrieved from http://www.eif.org.uk/wp-content/uploads/2015/03/EIF-Strand-1-Report-FINAL1.pdf

Goodman, R. (1997). The Strengths and Difficulties Questionnaire (SDQ). Journal of Child Psychology and Psychiatry, 38, 581-586.

Gutman, L., \& Schoon, I. (2013). The impact of non-cognitive skills on outcomes for young people: Literature review. A report for the Early Education Foundation and the Cabinet Office, Institute of Education, London. 
Harris, D. (1940). Factors affecting college grades: A review of the literature, 1930-1937. Psychological Bulletin, 37, 125-166.

Heckman, J. J. (2000). Policies to foster human capital. Research in Economics, 54(1), 3-56.

Jencks, C. (1979). Who gets ahead? New York, NY: Basic Books.

Lawrence, D. (1981). The development of a self-esteem questionnaire. British Journal of Educational Psychology, 51(2), 245-251.

Maughan, B., Taylor, C., Taylor, A., Butler, N., \& Bynner, J. (2001). Pregnancy smoking and childhood conduct problems: A causal association? Journal of Child Psychology and Psychiatry, 42, 1021-1028.

Murasko, J. E. (2007). A lifecourse study on education and health: The relationship between childhood psychosocial resources and outcomes in adolescence and young adulthood. Social Science Research, 36(4), 1348-1370. ISSN 0049-089X. Retrieved from http://dx.doi.org/10.1016/ j.ssresearch.2007.01.001

Nowicki, S., \& Strickland, B. R. (1973). A locus of control scale for children. Journal of Consulting and Clinical Psychology, 40, 148-154.

O’Connell, M., \& Sheikh, H. (2011). 'Big Five' personality dimensions and social attainment: Evidence from beyond the campus. Personality and Individual Differences, 50(6), 828-833.

O’Reilly, F., Daly, M., \& Delaney. L. (in progress). Associations between childhood self-regulation and adult socio-economic status: evidence from the British Cohort Study. Retrieved from http://www.cls.ioe.ac.uk/library-media\%5Cdocuments\%5CLethaby\%20Room\%20day\%201.pdf

Papageorge, N., Ronda, V., \& Zhengx, Y. (2015). The economic value of breaking bad: Misbehavior, schooling and the labor market. Baltimore, MA: Dept of Economics, Johns Hopkins University.

Parsons, S. (2014). Childhood cognition in the 1970 British Cohort Study. London: Data Note, Centre for Longitudinal Studies, Institute of Education. Retrieved from www.cls.ioe.ac.uk/shared/get-file. ashx?id=1969\&itemtype $=$ document $-273 \mathrm{k}$

Power, C., \& Elliott, J. (2006). Cohort profile: 1958 British birth cohort (National Child Development Study). International Journal of Epidemiology, 35(1), 34-41.

Richards, M., \& Abbott, R. (2009). Childhood mental health and life chances in post-war Britain Insights from three national birth cohort studies. London: Sainsbury Centre for Mental Health.

Richards, M., \& Huppert, F. A. (2011). Do positive children become positive adults? Evidence from a longitudinal birth cohort study. The Journal of Positive Psychology, 6(1), 75-87. doi:10.1080/17439 760.2011 .536655

Rosenberg, M. (1965). Society and the adolescent self-image. Princeton, NJ: Princeton University Press.

Rotter, J. B. (1966). Generalized expectancies for internal versus external control of reinforcement. Psychological Monographs, 80, 1-28.

Rutter, M., Tizard, J., \& Whitmore, K. (Eds.). (1970). Education, health and behaviour. London: Longman and Green.

Sacker, A., \& Schoon, I. (2007). Educational resilience in later life: resources and assets in adolescence and return to education after leaving school at age 16. Social Science Research, 36(3), 873-896.

Schoon, I. (2006). Risk and resilience: Adaptations in changing times. Cambridge: Cambridge University Press.

Schoon, I. (2008). A transgenerational model of status attainment; the potential mediating role of school motivation and education. National Institute Economic Review, 205(1), 72-82. doi: $10.1177 / 0027950108096590$

Schoon, I., Parsons, S., \& Sacker, A. (2004). Socioeconomic adversity, educational resilience, and subsequent levels of adult adaptation. Journal of Adolescent Research, 19(4), 383-404.

Silles, M. (2010). Personality, education and earnings. Education Economics, 18(2), 131-151.

Stott, D. H. (1966). Studies of troublesome children. London: Tavistock.

Stott, D. H (1969). The social-adjustment of children: Manual to the Bristol Social-Adjustment Guides. London: University of London Press.

Wadsworth, M., Kuh, D., Richards, M., \& Hardy, R. (2006). Cohort profile: The 1946 National Birth Cohort (MRC National Survey of Health and Development). International Journal of Epidemiology, $35(1), 49-54$.

Wadsworth, M. E. J. (2010). The origins and innovatory nature of the 1946 British Birth Cohort. Longitudinal and Life Course Studies, 1(2), 121-136. 
H. JOSHI ET AL.

Heather Joshi

UCL Institute of Education

United Kingdom

Bilal Nasim

UCL Institute of Education

United Kingdom

Alissa Goodman

UCL Institute of Education

United Kingdom 